\title{
Investigation on Building a Simulated Skill Training Platform for the E-commerce Students and Teachers
}

\author{
Dan Wang, Wenhao Li \\ Department of Information Technology, Huazhong Normal University, Wuhan, 430079, China \\ woaikaogu@126.com, whenhowlee@gmail.com
}

\begin{abstract}
To determine the need for simulated training of ecommerce activities prior to working in the real environment, we studied the views of undergraduates and college teachers from several aspects. Two hundred university students while also 200 college teachers were asked what the real problem was when they learned or taught in the e-commerce courses. Next, they were surveyed to inquire what knowledge they really need when students go to work positions and what type of job do they expect to have. Finally, they were asked whether using a simulated training platform would be beneficial. Through analysis, the aspects which are contained above we know that simulation should be incorporated into the education of e-commerce to students as a tool to practice their hands-on abilities prior to working. And from the survey we also obtain some useful information and references that may help us to design our electronic commerce training platform.
\end{abstract}

Index Terms—skills training; e-commerce training platform; questionnaire design; demand analysis

\section{INTRODUCTION}

With the continuous development of the Internet and its wide use, not only managed to change the way people communicate and learn, it has also brought a change in the way of business. E-commerce has become the fastestgrowing business model, with its high-speed development; some universities have set up e-commerce expertise. When teaching students practical abilities, the electronic commerce specialty ask for a particular emphasis on objective conditions, many universities have difficulties in providing practice opportunities to students.

In universities, training the students' practical activities are common difficulties, so how to design a useful web based electronic commerce training platform has great significance. By using the e-commerce training platform in the teaching process, which can improve students' practical activity, can also solve the problem in the from of practice, and provide great convenience for students to practice their ability.

This study attempted to investigate the college and university students and teachers to get the e-commerce

Manuscript received January 10, 2009; revised June 15, 2009; accepted July 17, 2009. undergraduates' and the teachers' interests in knowledge, skills, future post expectations and so on. Also to understand what the main problems are in the current teaching and study. So as to obtain the approximate understanding of the electronic commerce specialty, and offer the useful information or reference that may help us to design our electronic commerce training platform.

\section{LITERATURE REVIEW}

Students are likely to benefit from using the international simulated training platforms to do skill training rather than practice in the real environment. There are some existing research that describe some simulated projects which help student skill training.

Such as Sarah Parsons(2006)'s research, which adopts a qualitative case-study approach to report observations of, and comments from, two adolescent boys with ASDs, gathered during a series of sessions using a virtual cafe and bus environment. The participants' reactions gave encouraging support for the idea that VEs can be used and interpreted meaningfully by at least some students with ASDs.

In another study, Uzunboylu (2006), found evidence that the European Commission (EC) has positively affected European countries that have participated in these projects by providing necessary infrastructures and equipment, implementing teacher training, delivering useful content and services, encouraging cooperation and networking, promoting digital literacy, launching European virtual campuses, and supporting the use of the World Wide Web (WWW) for "e-Twinning" primary and secondary schools.

Vescoukis (2003) introduced a network-assisted educational structure for business simulation activities which can be considered as an alternative or a complement to on-the-job training activities in technical professional education.

Waller and Foster (2000) notes that students learn to operate the virtual instrument by using this program outside the laboratory. In their research, they used a virtual gas chromatograph-mass spectrometer (GC-MS) mounted on the World Wide Web to train students in instrument operation.

To determine the need for the simulated training of invasive procedures prior to working on patients, Arin 
K.Greene(2006) and David Zurakowski(2006) studied the views of physicians-in-training. Students and physicians were very interested in obtaining simulated training prior to practicing on patients. The more complicated the procedure, the greater the feeling that it should be simulated prior to attempting it on patients. From the articles mentioned above we can know that there has been a lot of researches to build a simulated training system.

All studies mentioned above suggest that simulation should be incorporated into the education of the students as a tool to practice activities prior to working in the real environment. In this study, we investigate the university students' and the teachers' attitude of using a simulated skills training platform. And we also attempt to collect some useful data for e-commerce knowledge structures, which the students should master. the teachers' common teaching methods, the students' interest in which type of professional knowledge and so no. Throw the research we try to find some useful information which may provide enlightenment when we start to built the simulated platform.

From above, the study aims at answering the following research questions:

1. What is the relationship between our country's electronic commerce specialize training targets and the current students' interests, as well as their employment expectations?

2. What skills do the students need to master their future work position?

3. Does their still have some prominent problems in the current teaching or learning?

4. What attitude do the students and the teachers have for the practice training courses? And what attitude do they have by using the electronic commerce simulated skills training platform?

5. From the investigating results, what can we achieve to help build the simulated skills training platform, or just things that can gain enlightenment from?

\section{MethodolOGY}

\section{A. Participants}

The survey is aimed at undergraduate students and college teachers.

The students' basic situation are: $43 \%$ of boys, girls accounted for 57\%; freshman accounted for $26 \%$, $27 \%$ sophomore, junior account for $22 \%$, and $25 \%$ senior; students surveyed in North China's accounting $12.15 \%$, to $8.84 \%$ in the Northeast, eastern China for $11.05 \%$, $34.46 \%$ for central China, southern China to $12.71 \%$, $9.39 \%$ for the Southwest, Northwest Territories for 9.39\%; of which $89 \%$ of the students belong to the teachers college, $11 \%$ for Comprehensive university.

The teachers' basic situation are: male for 54\% and female of 46\%; teachers surveyed in North and the Northeast both accounted for $7.6 \%$,eastern of China for $10.1 \%$, $44.3 \%$ for central, $12.7 \%$ for the Southwest, Northwest Territories for $11.4 \%$;about 51\% teaching above 5 years, 28\% above 3 years, only 6\% are just teaching for near 1 year.

\section{B. Questionnaire design}

Divided the questionnaire into two major parts, the first part of the survey is focused on basic information, such as students' gender, grade, types of institutions, the teachers' seniority, geographical distribution and so on, consequently, as the auxiliary data for the latter analysis.

In the second part of the questionnaire, mainly from five aspects to gather information, such as the needs of the professional knowledge types, the requirement of the professional skills, the expectation to the future posts, the main problems in the actual teaching, as well as the attitude about using the simulated skill training platform to assistant the practice teaching, then comparative analysis them, and provide feasible foundation to the ecommerce simulated skill training platform.

\section{Procedures}

This research uses the questionnaire survey procedure, in the process not only use the face-to-face way to send and receive the questionnaires, but also use the mail way to recover the answers from the participants especially to whom in the other province. Issued a total of 400 questionnaires, 372 valid questionnaires were recovered and the recovery is $93 \%$. Use the SPSS 15.0 software to analysis the data which were collected.

\section{RESULTS}

\section{A. The needs of the knowledge structure}

The top three knowledge types are: e-commerce applications, e-commerce knowledge management, knowledge-based network, respectively accounted for $15.5 \%, 13.1 \%, 12.1 \%$.

From the data collected it can be seen that most students need to strengthen knowledge in the knowledge of e-business applications, should not need to strengthen is the traditional knowledge of business. The current ecommerce students most need the knowledge about the application of professional knowledge, which is really the practice of professional experience, and the traditional theory of business knowledge is the least it needs to be.

The top three type of knowledge that teachers hope to strengthen are: e-business application knowledge, accounting for 15.5\%; e-business management knowledge, accounting for 15\%; e-commerce systems design knowledge, accounting for $14.2 \%$.

The first two statistics are the same, that is to say both teachers and students agree that the more important of the two types of e-commerce professional knowledge, the application knowledge and the management knowledge, but knowledge in the third category there are differences.

\section{$B$. The requirements of the e-commerce skills}

Students think the top five skills for e-commerce are: the e-commerce management technology accounted for $17.9 \%$, the network platform operation skills accounting for $17.3 \%$, the network marketing skills accounted for $13.8 \%$, the e-commerce systems development skills accounted for $13.0 \%$, and the e-commerce transaction skills accounted for $12.9 \%$. 
While teachers consider the top five skills of ecommerce are: the e-commerce management technology accounted for $16.2 \%$, the e-commerce transaction skills accounted for $16.2 \%$, the e-commerce systems development skills accounted for $15.6 \%$, the network platform operation skills accounting for $14.3 \%$, and the network marketing skills accounted for $12.3 \%$.

From the collected data we can know that teachers' and students' basic point of view are entirely consistent on the demand for the e-commerce skills, while the importance of these five skills are slightly different. At the same time, it can be seen that in the demand for ecommerce skills, the application skills still occupy the majority of the skills category, such as the abovementioned systems development, platform operations skills etc.

\section{The expectations of the future posts}

From the data we collected we can know the type of business accounted for 39.6 percent, management-type accounts for $34.2 \%, 24.1 \%$ technical, others $2.1 \%$.

The result from teachers is nearly the same as the students; they also think that most require e-commerce specialists are e-commerce business, e-commerce management, and the e-commerce technique.

So we can know that both students and teachers considered the most expected future post is the ecommerce business persons. How to become that kind of person is the most important question we should consider seriously. And the other kinds of people have little difference between the percentages.

\section{Analysis the teachers' teaching}

The top three commonly used teaching methods are: expository method accounting for 27.5 percent, 22.3 percent to discuss law, case methods of teaching for $20.5 \%$, task based learning accounting for 14.0\%, 9.6\% of virtual simulation experimental method, and $6.1 \%$ accounting for project-based Learning, like in Fig. 1.

Form the data, we know that the most frequently used method is the traditional method; the virtual simulation experimental method just accounted for $9.6 \%$, so it is very hopeful to use the simulated skill training system to help teachers' teaching .

About $62 \%$ of teachers thought the percentage of the experimental courses or the practical courses from the whole courses in their universities, about 62, are very low, 35 percent thought just appropriate, while just 3\% teachers thought it accounted for a large proportion.

Teachers think the best way to strengthen the undergraduates' abilities is social practice accounted for $49 \%$, simulated training accounted for $43 \%$, while $6 \%$ consider is graduate exercitation, and only $1 \%$ choose other options.

From the three question results we collected above, we can know that most universities or colleges are in a low percentage in establish experimental courses or the practical courses, on the other hand the teachers we investigated maintain that the most effective way to strengthen the undergraduates abilities is social practice.

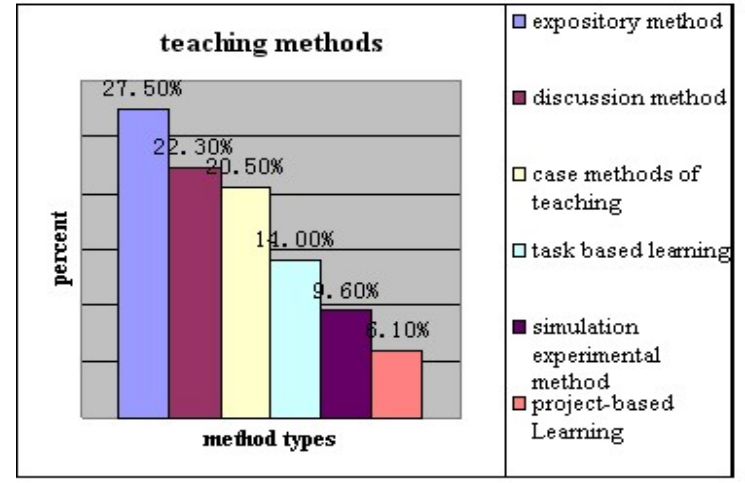

Figure 1. The teachers' teaching methods

Actually, most teachers are accustomed to use the traditional teaching method, namely, expository method. They do not use experimental method. From the analysis above, we can see there has a very obvious conflict between the actual teaching effort and the students' practical ability.

\section{E. The actual teaching problems}

Students believe in studying the top three problems, which are: lack of hands-on practice, accounting for 26.5\%; lack of related cases and learning resources, accounting for $19.9 \%$; most of the exercitation is in a virtual operating environment, accounting for 18.7 percent in Fig. 2.

While teachers think the most important problems are: weak convergence of social needs, accounting for $25.3 \%$; inappropriate simulate practical trainings, accounting for 22.4\%; less learning resources, accounting for 15.2 percent, $11.0 \%$ of unreasonable curriculum structure.

The students think the most important problem is lack of hands-on practice, while the teachers think it is weak convergence of social needs. In other words, both of them agree that the e-commerce students need to practice their skill in the real environment. Also both of them consider that the related cases and learning resources are imperative.

\section{F.Views on the application training platform}

26.1\% students believe that social practice is an effective way to train their professional skills, there are also $25 \%$ of the students think that practical training is more effective, $19.6 \%$ of them consider is simulate operation, $14.7 \%$ think is case study, and $14.5 \%$ of them believe that graduate training is an effective way.

$65 \%$ of the students believe that the simulate practical training platform will bring great help and will thusly take full advantage for practical training; $31 \%$ of the students think it is from individual to individual and vary from school to school; only 1\% of them believe that there will not too much help in Fig 3.

$86.1 \%$ of the teachers believe the simulate practical training platform will bring a great help and will take full advantage for practical training; $10.1 \%$ of them think the effects are normal; only $3.8 \%$ of them believe that there will not too much help for the students' training. 
From the data analyzed above, we can know that teachers hold a more significantly supportive attitude toward the use of the simulated training skill platform.

\section{DISCUSSION}

\section{A. The difference between the e-commerce cultivating goal and the expectations of the future posts and the students' learning interests}

In universities and colleges, which have set the ecommerce, its personnel training goal asks that they should adapt to the needs of society-oriented and talentbased business and technical personnel for e-commerce students must have the appropriate knowledge and capacity structure. It requires students to master the theory of modern commerce and e-commerce knowledge and expertise, computer-related applications and network application skills, be able to engage in e-commerce website construction and management, operation and maintenance of the network marketing business or firstline logistics management needs, all-round development of complex, high-level vocational-technical applications personnel.

From the data collected, it can be seen that the students' interests in jobs are consistent with their expectations, but our e-commerce and professional training objectives has big difference. Because the teachers' expectations to the future posts that their students should take are almost the same with the students', so in class, teaching also has a different goal from the cultivation goal.

The difference between training objectives and the expectations of students leads to professional employment in the form of the employment situation and the actual existence which reasons for conflict. How to solve the problem when the students and the teachers using our simulated skill training system, is an important question we should consider carefully.

As a result, practical training in the e-commerce platform for the design process, taking fully into account the specific conflicts. How to motivate students and maintain knowledge of different types of learning and sustaining motivation is practical training platform for the design of the primary issues is also one of the most important issues. Which strategies should be used and how to use so as to arouse and keep the students' learning interests, and what methods would much better to help the teachers use the training system, the two questions mentioned above are the most significant and foremost ones which we should consider carefully.

\section{$B$. The needs of the knowledge structure reflect the the extreme thirst for application knowledge}

The invest in knowledge and the structure of demand, students can be seen on the application of e-commerce knowledge of the needs of the largest, that is to say that the practice of self-learning curriculum is what the students most need. At present, e-commerce expertise combined with the actual situation, we can see that this is the profession and the current need to be solved and is a

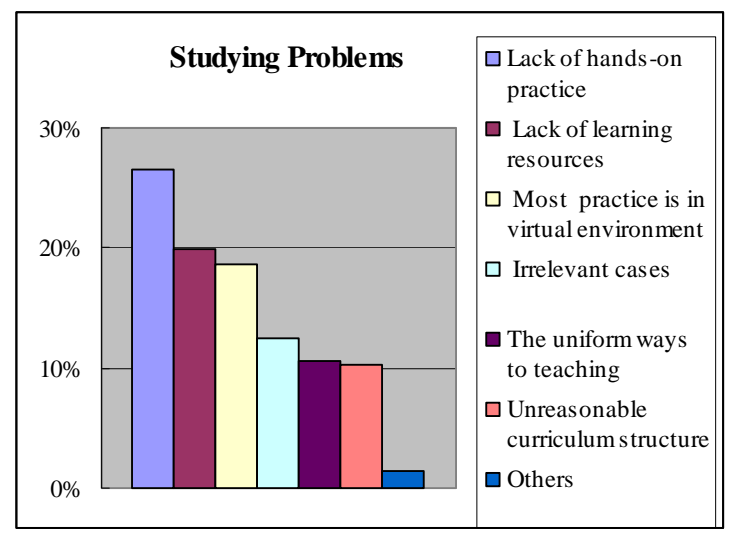

Figure 2. The students' view of the training platform

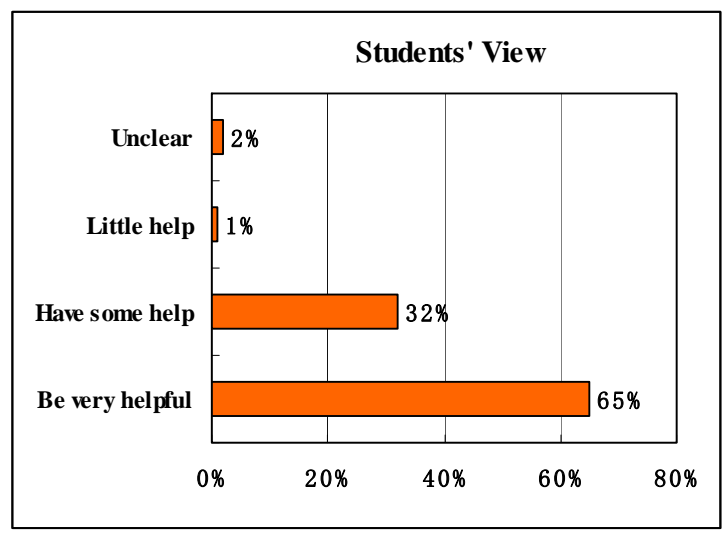

Figure 3. The students' view of the training platform

major problem. Through the use of e-commerce platform for practical training, students can apply knowledge of ecommerce needs. Students, through a virtual on-line practice, also can have an effective application of knowledge and practical experience, and will be able to use this knowledge and experience for practical work in the future, this should be the practical training of ecommerce platform is designed. The design process should this goal, in virtual activities designed to be considered in reality and in all cases that may arise so that students in the virtual environment can be reflected in the activities of the most real, so students can accumulate real useful practical experience.

\section{C.The expectations to the professional skills look forward to reflect the diverse needs of knowledge}

From the e-learners the skills required for jobs statistics, we can see that the profession itself, needs more knowledge and miscellaneous skills, only further knowledge of the organization in order to build a sort of reasonable knowledge structure of the system. Training of this platform of knowledge in the organization must also put forward the request and at the same time on the practice of practical training platform design activities have also put forward higher requirements. Due to complicated types of knowledge, how to design different practical activities to cover the vast majority of the main 
content of knowledge, practical training for e-commerce platform design activities from another point of view also put forward new demands.

\section{D.The contradiction between the current teaching in the universities and improve the students' abilities}

From the investigation of teachers we know that most of them are still used to the traditional method of teaching, expository method, while e-commerce students need much more practice experience or training to apply theories to practice, so the expository method is not fit enough to the current status. On the other hand, the teachers' teaching methods are too singleness, just use one method in class teaching can not help the students understand the knowledge more clearly.

Besides the curriculum instruction in universities is illogical that the practical courses are just having a very little percentage from the whole instruction. From above we know that training the students' skills is not only the students' request but also the teachers' hope and actual environment's demand. The practical course is a useful way for training the students, so we should pay more attention to it, but it is so difficult to find so much chances to let the students practice their skills in the actual working environment, moreover create a simulated skill training system is also effective to resolve the problems. So we should make the virtual training system more similar to the real work environment, so the Scenario design in the system becomes very important.

\section{D.Both of the students and the teachers consider the} problems in the current teaching are basically same

By using the questionnaire we investigated the students and the teachers to determine what the real problem is and see what we can do in the current teaching or learning separately.

Both students and teachers agree to design more related application cases and other learning resources to support teaching and learning. The simulated skill training platform for the design process, not just focus on the design of practical activities, resources for the case is designed for a practical training platform designed to focus on the contents of the other. How will the existing resources in case of finishing sections, so that these cases can provide students with a useful application of ecommerce knowledge, practical training in the design phase of the platform needs to give serious consideration to the issue.

In addition, from the data we can see that most students refer to doing practice in the real environment. That is means, the current virtual training systems are not so good to allow students to think they are doing the practice in a real world, and it also can know that the systems are not very useful to help the students training their application skills. And some of the students say that the current teaching cases are short of pertinence and timeliness.

From the information above we know that when we start building our skill training platform, the situation we create must be more real and the cases which contained must be more helpful and targeted.
In the teacher's opinion, the most important problem in the current teaching is there is not enough connection to the social need. It means that the current knowledge which teachers teach to the students is not so helpful when the students graduate from school. Most of the teachers are aware of the conflict between the current cultivate goal and the work expectations. But how to help the students strengthen their working skills in school especially when the material is an undecidable for them, it is obviously that they take the simulated skill training platform in use as an effective way to solve the problem. So some teachers consider there is not enough simulated skill practice in the current school teaching.

In a word, students' opinion is focus on practicing their skills; the teacher's opinion is concentrate on how to strengthen the students' practical skills. So the training platform we build must focus on how to improve the students' practical abilities effectively.

\section{E.Both of the students and the teachers take the supporive attitude to build the simulated skill training platform}

About 65\% students and $86 \%$ teachers believe that simulated practical training platform will bring a great help and will take full advantage for practical training. The teachers take a more supportive attitude than the students, but most of them think the training platform is useful, so building a simulated skill training platform to help the students improve their practical skills is necessary. And both of them have a great hope to the platform especially the teachers, so we should create a real useful system.

\section{CONCLUSION}

\section{A.Construct the e-commerce knowledge instruction}

There is a conflict between the current school cultivation goals and the knowledge of instruction, so when we construct the skill training platform's knowledge instruction we should know that the ecommerce application knowledge is the most important one. We must build the instruction from three aspects: the e-commerce application of knowledge, the e-commerce management knowledge and the e-commerce technical knowledge. And from the investigation we also know that there are a lot of specific curriculums that students should learn and commend. So under each aspect there still some kind of knowledge should be learned. Such as under the e-commerce management knowledge there are ecommerce operation management, e-commerce project management, e-commerce information management, ecommerce marketing management, e-commerce logistics management, e-commerce safety management, and law of e-commerce. While under the e-commerce safety management there still some types of knowledge like safety management system, risk management, system security, credit management and so on. From the different types of knowledge we mentioned above can come to a conclusion that there are so many kinds of knowledge the students should be familiar with, it means in our 
simulated skill training platform there also have so many types of knowledge should be contained.

So from the specific data collected we can make a clear knowledge instruction that students required or the teachers hoped. And it is also very important to structure the e-commerce knowledge instruction carefully and clearly.

\section{B.Create and implement the platform environment}

The students ask for a more real environment to practice their skill when in a virtual system, so the platform's environment should be more verisimilitude, that is mean the practice which the students take in the platform must the same as that in the future work. Every step the students take in the platform must the proximal to the real work.

There should be several practice environments to help students experience the different type of work in the future, so as to help them get in the groove quickly. In the design of the training platform we want to make a main simulated training system, a question deducing system, a practice testing system and a venture training system. Moreover, there are two special modules; the one is the role guided animation package, the other is the melodrama cases package. That is means in our ecommerce simulated skill training platform contain several modules, each module has its own function, the details we will describe the detail in the following context.

\section{C.The conception to the platform's structure design}

By analyzing the data we collected, we can have a preliminary plan for our training platform (like Fig.4), we is that the simulated training system. Now we start to explain them one by one.

The e-commerce simulated integrating skill training platform can be separated into two parts, one is about knowledge and sources, and the other is for training., with each part having several modules. In the knowledge and resources part, it contains the role guided animation package; the melodrama cases package, and the knowledge and skill base. In this part, students should not do any practice, they just see the cases or knowledge is enough. So we suggest the teachers can use this part in their theory teaching lessons, by analysis the cases the students can understand more clearly on how to use the knowledge they learned in the class. It can also be use after the lessons; the students can look at it in their spare time or self learning time, so as to make up for their less hand-on practice experience. In the other part, it contains about four maim systems, the simulated training system, the question reducing system, the practice testing system, and the venture training system. Each system has its own function on training the students' ability. This part can be used on the practical courses, students can trying the system by themselves, and also can try it with several other people like a group; the teachers also can use this part as a classroom display, to help the students understand the e-commerce business process clearly.

The role guided animation package uses the flash technology to make animations, from different point of view of the cases, and stand on the specific role's view to show the e-commerce activities. So we have to choose a specific cases to analysis and find out the key dominant

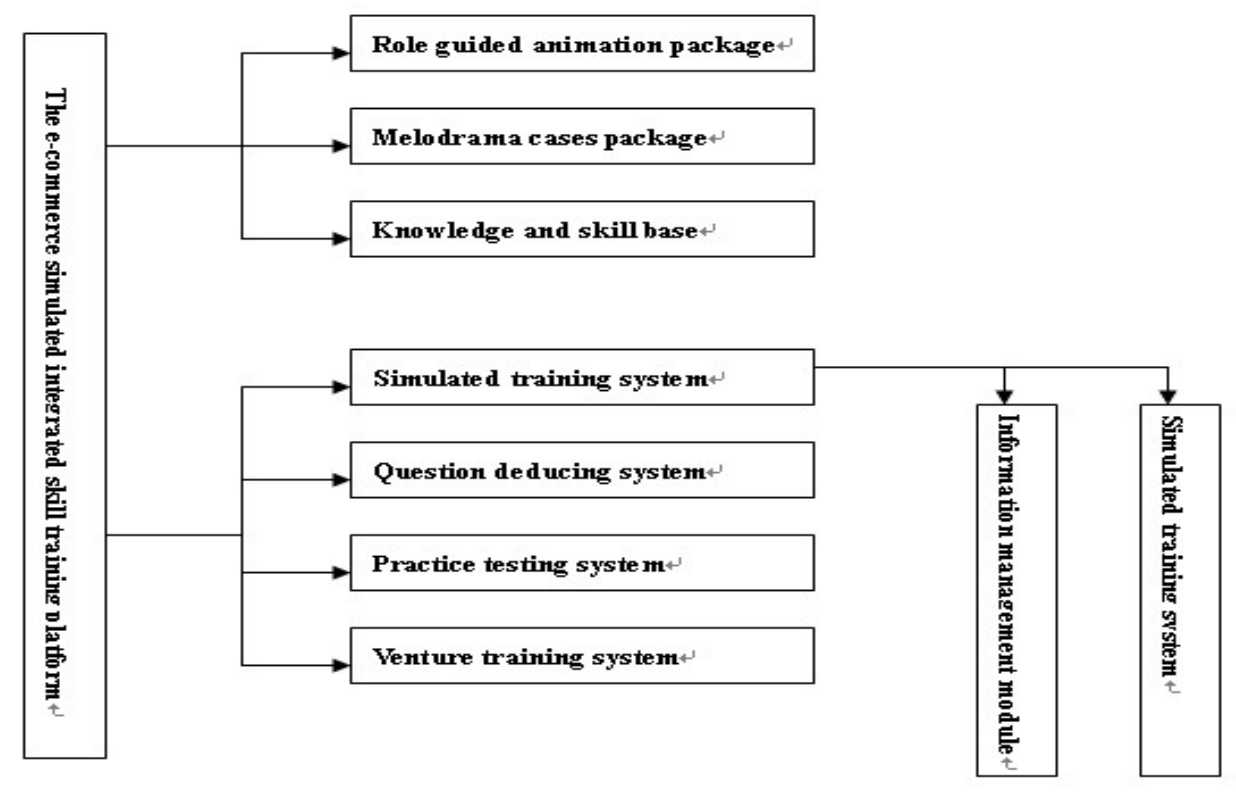

Figure 4. The platform's structure.

can get the platform's structure and each module should take what function. Now we start to explain our idea of our simulated skill training platform. Firstly, it must be an integrated platform which contains the specific context of knowledge, some cases that related to the real ecommerce business process, and the most important part roles in the cases, we also have to find out the processing steps which the roles should take in the case. At the same time, in order to bring into correspondence with the melodrama cases package, each role in the role guided animation package keys from the melodrama cases package. That means all the roles are real instead of 
virtual, it is much easier for students to understand. From the above description it can be seen that keying the characters from the video and summarizing the activities' steps is difficult point in the module.

Contrary to the role, guided animation package, this package tries to use some complete melodramas to reveal the contents of the cases, so it helps the students understand the cases more intuitionisticly. The melodrama cases package take a lot of little videos, which imitates real e-commerce business scene. And each video is an e-commerce business case, so watching the cases the students can become familiar with the business process in a real environment and enhance the sense of reality. So we should choose the cases clearly, and try as much as possible to make the scene more real. Before we film the cases, we should make the scripts carefully and use as much details as possible.

The knowledge and skill base contains three subtreasuries, and almost 800 items. The base contains the main theories and application skills which the students should master. It can be an ancillary tool for teachers' teaching, and it also can help students sort out their knowledge structures. In use, students can start learn from any where by need. The knowledge and skill base contains three main components, the e-commerce management knowledge, the e-commerce business knowledge and the e-commerce technical knowledge. In each component still has several categories, while in each categories there also have several little items. For example, under the e-commerce management knowledge there are e-commerce operation management, ecommerce project management, e-commerce information management, e-commerce marketing management, ecommerce logistics management, e-commerce safety management, and law of e-commerce. While under the ecommerce safety management there still some types of knowledge like safety management system, risk management, system security, credit management and so on.

The simulated training system contains two parts, the information management system and the experiment system. This system is the core of simulated skill training platform, the student's use the experiment system to doing the virtual practice activities, the information management system is used to manage the students' login information. In the experiment system, every step of the experiment must be strict compliance with the actual ecommerce activities; so as to help the students can really master the e-commerce application skills and the steps of the real e-commerce business activities by doing practice training in the simulated skill training platform.

The question deducing system is another characteristic for the training platform. It points at several main problems which students maybe encounter. Firstly, the question deducing system provides a question base which contains the frequently asked questions. When the students meet the question their first time, they can go to the FAQ base to try to find the answers. If they can not find the question answer, they can add their question in to the FAQ base. When other students or teachers find their questions, they can give the answer to the question; the students who raise the question also can give the answer in the FAQ base. While the process from raise question to find the answer is also the process of the question deducing.

The practice testing system includes two types of test content. One is for the students' theories knowledge testing, students answer the question on the web and the system gives the score immediately. The other is to test the students' level to master the e-commerce application skills, this test can be separate into two types, one is the online question test, the other is by limit the specific contexts and role to let the students complete the ecommerce activity by themselves in a certain period of time, then the system will give the conclusion. The key point to this system consists in the establishment of the online test question base and the evaluation criterion to the students' application skills.

The venture training system is a system which analogous to the network game system. It limits the characters and conditions; let the students' comprehensive use of the knowledge in the virtual environment to become self-employed. In this system, the students are more likely to develop freely. Across the complete process of venturing can help the students master the e-commerce theory knowledge and the application skills more proficiently; in the mean time it can also help the students clear their deficiencies. In other word, the venture training system is try to train the students' abilities to use the skills generally.

From this research it can be found that e-commerce specialty is a young and mixed specialty, and its expertise is in complex and highly practical. How to adapt to the design of our current e-commerce features of the professional and at the same time be able to effectively stimulate and sustain the motivation of learners to study e-commerce platform for practical training, requires us to make comprehensive use of instructional design theory, computer knowledge and technology.

\section{ACKNOWLEDGMENT}

The authors wish to thank the Scientific Research Fund of Chinese Higher Education Teaching Research Center (Grant No. 20080412), by which the research project has been supported.

\section{REFERENCES}

[1] Yu-Chu Yeh, “Aptitude-treatment interactions in preservice teachers' behavior change during computersimulated teaching”, Computers \& Education, 11, 2006, 495-507.

[2] Arin K.Greene and David Zurakowski, "Determining the Need for Simulated Training of Invasive Procedures", Advances in Health Sciences Education, 11, 2006, 41-49.

[3] Sarah Parsons and Anne Leonard, "Virtual environments for social skills training: comments from two adolescents with autistic spectrum disorder”, Computers \& Education, 47, 2006, 186-206.

[4] Uzunboylu. H, "A review of two mainline E-learning projects in the European Union”, Etr\&D-Educational 
Technology Research and Development, 54, 2006, 201209.

[5] Vescoukis, V. C. and S. Retalis, "Network-based business simulation activities in technical professional education”, Interactive Learning Environments, 11, 2003, 169-191.

[6] Waller, J. C. and N. Foster, "Training via the web: a virtual instrument”, Computers \& Education, 35, 2000, 161-167.

[7] Sarah Parsons and Anne Leonard, "Virtual environments for social skills training: comments from two adolescents with autistic spectrum disorder”, Computers \& Education, 47, 2006, 186-206.

[8] Nancye E. McCrary and Joan M. Mazur, “Conceptualizing a narrative simulation to promote dialogic reflection: using a multiple outcome design to engage teacher mentors”, Etr\&D-Educational Technology Research and Development, 2008.

[9] Carlos A. Jara and Francisco A. Candelas, "Real-time collaboration of virtual laboratories through the Internet", Computers \&Education, 2008.
[10] Nigel W. John, "The impact of Web3D technologies on medical education and training”, Computers \& Education, 49, 2007, 19-31.

Dan Wang (1985- ), postgraduate of the department of information technology in Huazhong Normal university, Wuhan, China, research area for knowledge management and teacher professional development.

Wenhao Li (1978- ), doctor, lecturer of the department of information technology in Huazhong Normal university, Wuhan, China, research area for knowledge management, learning system design and architecture, and teacher professional development etc.

Address for correspondence: Wenhao Lee, Department of Information Technology, Huazhong Normal University, Wuhan, 430079, China , Email: whenhowlee@gmail.com 